\title{
Preferences of dairy cows for three stall surface materials with small amounts of bedding
}

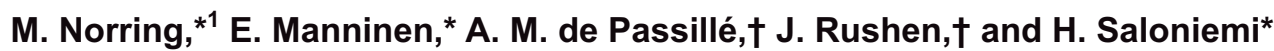 \\ ${ }^{*}$ Department of Production Animal Medicine, PO Box 57, 00014 University of Helsinki, Finland \\ †Pacific Agrifood Research Centre, Agriculture and Agri-Food Canada, PO Box 1000, 6947 Highway 7, Agassiz, BC, Canada, V9M 1A0
}

\begin{abstract}
Farmers' concerns about the economy, cost of labor, and hygiene have resulted in reduced use of organic bedding in stalls for dairy cows; however, the reduced use of organic bedding possibly impairs cow comfort. The effects of different stall surface materials were evaluated in an unheated building in which only a small amount of bedding was used. The lying time and preferences of 18 cows using 3 stall surface materials (concrete, soft rubber mat, and sand) were compared. All materials were lightly bedded with a small amount of straw, and the amount of straw added to each stall was measured. The cows only had access to stalls of one surface type while their lying time was observed. Lying times were longest on the rubber mats compared with other surfaces (rubber mat 768; concrete 727; sand 707 $\pm 16 \mathrm{~min} / \mathrm{d}$ ). In a preference test, cows had access to 2 of the 3 types of stalls for $10 \mathrm{~d}$ and their stall preference was measured. Cows preferred stalls with rubber mats to stalls with a concrete floor (median 73 vs. 18 from a total of 160 observations per day; interquartile range was 27 and 12, respectively), but showed no preference for sand stalls compared with stalls with a concrete floor or with rubber mats. More straw was needed on sand stalls compared with concrete or mat $(638 \pm 13$ $\mathrm{g} / \mathrm{d}$ on sand, $468 \pm 10 \mathrm{~g} / \mathrm{d}$ on concrete, and $464 \pm$ $8 \mathrm{~g} / \mathrm{d}$ on rubber mats). Lying times on bedded mats indicated that mats were comfortable for the cows. If availability or cost of bedding material requires limiting the amount of bedding used, rubber mats may help maintain cow comfort.
\end{abstract}

Key words: bedding, behavior, dairy cow, lying

\section{INTRODUCTION}

Flooring in stalls for dairy cows should be comfortable enough to ensure that cows use the stalls and that they have sufficient resting time for their welfare and

Received February 25, 2009.

Accepted August 19, 2009.

${ }^{1}$ Corresponding author: marianna.norring@helsinki.fi production. Cows prefer to lie on soft flooring (Jensen et al., 1988; Herlin, 1997; Tucker et al., 2003), and the softness of the lying surface is influenced by the amount of bedding. Straw bedding increases thermal insulation in stalls (Tuyttens, 2005), which is important when cattle are housed in unheated buildings. Farmers often reduce the amount of bedding to save bedding costs and improve udder hygiene. Increasing the softness of stall flooring might compensate for a reduced use of straw bedding (Jensen et al., 1988; O'Connell and Meaney, 1997). Sand has increased in popularity as a bedding material because it is economical, improves cleanliness, and has advantages for leg health (Cook, 2003; Espejo et al., 2006; Norring et al., 2008). Manninen et al. (2002) found that cows preferred concrete-based stalls with plenty of straw to soft rubber mats with a small amount of straw and to sand without organic bedding, but the large amount of straw present might have been critical for the cows' choices.

The objective was to compare resting behavior and preferences of dairy cows for 3 kinds of stall surface when used with only a small amount of straw bedding.

\section{MATERIALS AND METHODS}

\section{Animals and Housing}

A total of 18 multiparous (2 to 7 lactations) Friesian dairy cows weighing $615 \pm 77 \mathrm{~kg}$ with 12 mo milk production of $6,874 \pm 1,193 \mathrm{~kg}$ (mean $\pm \mathrm{SD}$ ) was used. Cows had calved between 1 and 7 mo before the beginning of the test. Grass silage (DM 30\%) and water were supplied ad libitum and concentrates (mixture of barley and oats) were provided from an automatic feeder, the amount varying according the milk production of the cow. Cows were milked twice daily, at 0600 and $1700 \mathrm{~h}$, in a milking parlor situated in an insulated building.

Before the tests began, the cows were housed in an insulated freestall barn with concrete stalls covered with a hard rubber mat and a mixture of peat and cut straw. During the previous winter or summer for 6 to $10 \mathrm{wk}$, the cows had been included in other experiments with the same surface materials (Manninen et al., 2002) 
as in the present study. Thus, the cows were familiar with the stalls and the materials.

\section{Procedures}

During the experiments, the cows were kept in an unheated, uninsulated freestall barn. The stalls and alleys were cleaned twice daily and the normal feeding and milking schedules were followed. Three stall surface materials were tested during winter when the temperature in the barn varied from -20 to $+8^{\circ} \mathrm{C}$. The barn was divided into 4 pens with 6 stalls in 1 row (see Manninen et al., 2002). Three rooms were used as test rooms and one as a holding room for cows not in the study. In the holding room there were 9 stalls with peat bedding on either concrete or on plywood placed over a sand base.

Three stall surface materials were used: concrete, sand (particle diameter 0.1 to $0.6 \mathrm{~mm}$ ), and soft rubber mats (Cloud 9, NRI Inc., Toronto, Canada; Manninen et al., 2002; Rushen et al., 2007). Sand stalls were created by adding a 20-cm layer of fine sand on sand base with particles of different size. The rubber mats were placed on sand-based stalls covered with plywood. All stalls were bedded at the beginning of the experiment with a small amount $(2 \mathrm{~kg})$ of cut barley straw. Soiled straw and sand were removed when the stalls were cleaned. Sand was added to stalls as needed to keep the base constant. Extra straw was added every other day so that the stall floor was covered with a thin layer of straw barely keeping the surface covered when dispersed evenly. The amount of straw added to each stall was weighed at each addition.

In the preference tests, each group of cows was allowed to choose between 2 of the 3 different types of materials, and different pairwise comparisons were made in different rooms. Each pen of 6 stalls contained 2 of the materials; that is, concrete versus sand, rubber mats versus concrete, and sand versus rubber mats, so that 3 stalls had one type of material and 3 stalls had the other material. Stalls with different materials alternated within rows in each pen.

The cows were divided into 6 groups of 3 cows. The groups did not differ in age, milk production, BW, or DIM. All 6 groups of cows were tested with all 3 comparisons for 3 wk per comparison following a balanced order. Three of the groups were tested at the same time while 3 others were kept in the holding room.

To ensure that the cows had experience with both materials in each preference test, a forced-choice phase initiated the test session. During the forced-choice phase, the cows were allowed access to only 3 stalls with one type of material. Stalls containing one type of material were closed off for $5 \mathrm{~d}$ and stalls containing the other material were closed off for the next $5 \mathrm{~d}$ following a balanced order across groups. Stalls containing the material that was closed off for the last 5 -d period were opened for 1 extra day before starting the $10-\mathrm{d}$ preference test to provide balanced exposure to both materials.

The experiment was approved by the animal ethical committee, and the experiments were managed in a manner that avoided any additional discomfort to the normal production environment.

\section{Observations}

The behavior of the cows was video-recorded. In each test room a camera (black and white with wide lens) was placed to film the entire row of stalls. The camera was placed $7.4 \mathrm{~m}$ from the nearest stall. All cameras were fed into a single video recorder using a multiplexer. For purposes of identification, cows with similar coat patterns were marked with hair dye. Cows were filmed continuously for $24 \mathrm{~h}$ on d 1,4 , and 5 of the forced-choice period. During the preference tests, cows were filmed for $24 \mathrm{~h}$ on $5 \mathrm{~d}$ (on d 1, 3, 5, 7, and 10) after opening both types of stalls. One observer analyzed the videos from all forced-choice and preference test days.

\section{Behaviors}

During forced-choice periods, the times the cow was lying down (weight off all 4 feet) and standing up (standing on all 4 legs) were observed using continuous observation. During preference tests, scan sampling was used (Observer, Noldus Information Technology Inc., Wageningen, the Netherlands) for each stall and always in the same order. The identities of cows lying in the stalls were recorded every 9 min. A total of 160 observations was made for each stall during each 24 -h recording.

\section{Statistical Methods}

Differences between materials during forced-choice periods in total lying time per day as well as in the duration and total frequency of lying bouts were tested with mixed model analysis (SPSS 15.0, SPSS Inc., Chicago, IL). The average values of groups and $3 \mathrm{~d}$ were used for analysis. Test period was used as a repeated measure. Flooring material was inserted as a fixed factor and group as a random factor. Toeplitz covariance structure provided the best model fit. The average weight of straw added to each stall during the forced-choice period was analyzed with an independent samples $t$-test using stall as the observational unit. Results are expressed as mean $( \pm \mathrm{SE})$. The preference of cow groups for stall material 
Table 1. Mean ( \pm SEM) total duration of time spent lying down per day, mean duration of lying bouts, and frequency of lying bouts of 18 cows during the forced-choice phase

\begin{tabular}{lcccc}
\hline Behavior & Rubber mat & Concrete & Sand & SEM \\
\hline Total lying time, min/d & $768^{\mathrm{a}}$ & $727^{\mathrm{b}}$ & $707^{\mathrm{b}}$ & 16 \\
Mean duration of lying bouts, min & 71 & 76 & 71 & 3.3 \\
Total number of lying bouts/d & 11.1 & 9.9 & 10.6 & 0.52 \\
\hline
\end{tabular}

${ }^{\mathrm{a}, \mathrm{b}}$ Within rows, numbers with different superscripts differ significantly.

${ }^{1}$ Lying time: mat versus concrete $(P=0.039)$; mat versus sand $(P=0.007)$.

during test days was analyzed with a Wilcoxon test for related samples. The average number of lying observations of a cow group was used in the analysis. Results are expressed as median and interquartile range.

\section{RESULTS}

During the forced-choice period when the cows had access to only 1 type of stall, there were significant effects of stall flooring material on the total duration of time spent lying $(P=0.018)$, but no effect on the frequency of bouts of lying down $(P=0.16)$ or the mean duration of lying bouts $(P=0.35)$. The total duration of lying down was higher on the rubber mat compared with concrete or sand (Table 1). More straw was needed on sand $(638 \pm 13 \mathrm{~g})$ than on concrete $(468 \pm 10 \mathrm{~g})$ or on rubber mat stalls $(464 \pm 8 \mathrm{~g} ; P<0.001)$.

In the preference test comparing rubber mats and concrete stalls, cows were observed lying down more often on rubber mats than in concrete stalls (73 vs. 18 observations per day, interquartile range: 27 vs. 12; Figure 1). Cows showed no overall preferences between rubber mats and sand stalls (50 vs. 40 observations per day, interquartile range: 29 vs. $23 ; P=0.25$ ) or between sand and concrete-based stalls (42 vs. 42 observations per day, interquartile range: 8 vs. $10 ; P=0.91$ ).

\section{DISCUSSION}

Cows reclined longer in stalls with soft rubber mats compared with sand- and concrete-based stalls when there was only a small amount of straw in freestalls. When the stalls were all bedded with the same small amount of straw, the cows preferred stalls with soft rubber mats over those with concrete. This supports the results of O'Connell and Meaney (1997), who showed that cows preferred rubber mats over concrete with the same kind of sawdust bedding. Herlin (1997) found that cows preferred soft rubber mats to conventional, hard rubber mats or concrete when 2 to $3 \mathrm{~kg}$ of new bedding per stall was added.

Furthermore, resting time was highest in the stalls with rubber mats during the forced-choice period. Our results support those of Rushen et al. (2007), who noted that cows tended to rest longer in rubber mat-based stalls than in concrete-based tie-stalls with $0.5 \mathrm{~kg}$ of straw bedding. Total duration of lying per day can be used as a measure of cow comfort (Haley et al., 2001). In addition to observed advantages of rubber mats on resting behavior, the least amount of straw needed to be added to rubber mat and concrete stalls during the experiment. The air layer underneath the rubber mat could have improved its thermal properties during winter temperatures that ranged from -20 to $+8^{\circ} \mathrm{C}$. The use of soft rubber mats may provide a means for bedding management with only a small amount of straw while maintaining cow comfort in unheated buildings.

The advantages of sand-based stalls for cow comfort were far less obvious. The cows showed no preference for sand stalls over stalls with concrete floors and resting time was not longer. Furthermore, larger quantities of straw had to be added to maintain a constant coverage of bedding as straw was mixed in with sand particles. Despite higher amounts of added straw on sand stalls, a greater area of sand might have been bare during the experiment, contributing the reduction of lying times. In our previous preference tests, in supporting Tucker et al. (2003), cows avoided sand stalls without bedding, and time spent lying down was shorter compared with other materials (Manninen et al., 2002; Norring et al., 2008). Yet, extended earlier experience of sand for at least 2 lactations (Tucker et al., 2003) or at least 21 wk (Norring et al., 2008) increased the acceptance of sand, but bare sand never appeared as the preferred lying surface material. It is possible that the earlier experience of some weeks during the previous year could have increased the preference for sand in this study compared with the findings of Manninen et al. (2002). More studies are needed to determine if raising young animals on sand would affect their preferences, because the animals we used had not had access to sand as calves.

Sand bedding improves hoof health and heals hock lesions (Espejo et al., 2006; Norring et al., 2008). Therefore, there seems to be a trade-off between improved hoof health and reduced cow comfort with the use of sand bedding. In future studies it would be interesting to investigate if a combination of sand with straw 

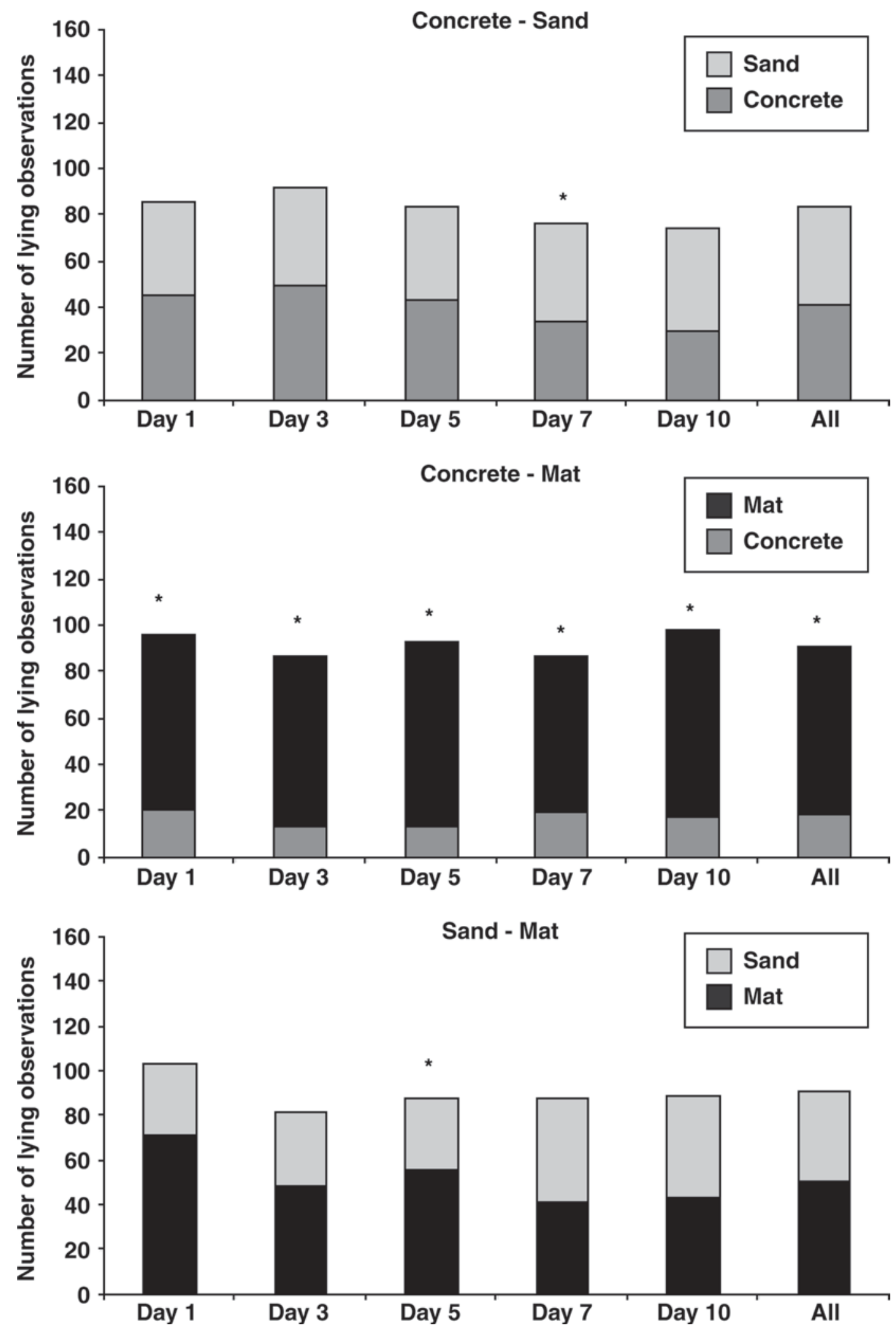

Figure 1. The lying observations during the 10 -d preference test and the average preference for stall material. Cow groups $(\mathrm{n}=6)$ were tested for all the dual combinations of stall materials. The figure shows the median values of lying observations; the maximum number of observations per $24 \mathrm{~h}$ was 160 . Cows preferred rubber mat over concrete stalls when a small amount of straw was used. On other materials, cows showed no overall preference. ${ }^{*} P<0.05$. 
or some other soft material could convey the health benefits and maintain lying time.

Combined with the findings of Manninen et al. (2002), where the rubber mat stalls were similar to those used in this experiment, it seems that cows preferred the stalls with the softest flooring, which could be achieved by using either deep straw bedding or soft rubber mats. Adding straw on sand increased its use relative to mats, whereas reducing the amount of straw on concrete decreased its use relative to mats. In accordance with Tucker and Weary (2004) and Tucker et al. (2009), the amount of bedding seems to affect the lying preferences of cows on concrete and sand. The insulating and softening properties of straw can make it preferred by cows.

In conclusion, installing soft rubber mats on concrete stalls can ameliorate the adverse effects of reduced bedding on lying behavior. Lying times on mats indicated that mats were comfortable for the cows compared with concrete and sand bases. It appears that when a small amount of straw is available, cows lie down more on soft rubber mats.

\section{REFERENCES}

Cook, N. B. 2003. Prevalence of lameness among dairy cattle in Wisconsin as a function of housing type and stall surface. J. Am. Vet. Med. Assoc 223:1324-1328.

Espejo, L. A., M. I. Endres, and J. A. Salfer. 2006. Prevalence of lameness in high-producing Holstein cows housed in freestall barns in Minnesota. J. Dairy Sci. 89:3052-3058.
Haley, D. B., A. M. de Passillé, and J. Rushen. 2001. Assessing cow comfort: Effects of two flooring types and two tie stall designs on the behaviour of lactating dairy cows. Appl. Anim. Behav. Sci. $71: 105-117$.

Herlin, A. H. 1997. Comparison of lying area surfaces for dairy cows by preference, hygiene and lying down behaviour. Swed. J. Agric. Res. 27:189-196.

Jensen, P., B. Recén, and I. Ekesbo. 1988. Preference of loose housed dairy cows for two different cubicle floor coverings. Swed. J. Agric. Res. 18:141-146.

Manninen, E., A. M. de Passillé, J. Rushen, M. Norring, and H. Saloniemi. 2002. Preferences of dairy cows kept in unheated buildings for different kind of cubicle flooring. Appl. Anim. Behav. Sci. 75:281-292.

Norring, M., E. Manninen, A. M. de Passillé, J. Rushen, L. Munksgaard, and H. Saloniemi. 2008. Effects of sand and straw bedding on the lying behavior, cleanliness and hoof and hock injuries of dairy cows. J. Dairy Sci. 91:570-576.

O'Connell, J. M., and W. J. Meaney. 1997. Comparison of shredded newspaper and sawdust bedding for dairy cows: Behavioural, clinical and economic parameters. Ir. Vet. J. 50:167-170.

Rushen, J., D. Haley, and A. M. de Passillé. 2007. Effect of softer flooring in tie stalls on resting behavior and leg injuries of lactating cows. J. Dairy Sci. 90:3647-3651.

Tucker, C. B., and D. M. Weary. 2004. Bedding on geotextile mattresses: How much is needed to improve cow comfort? J. Dairy Sci. 87:2889-2895.

Tucker, C. B., D. M. Weary, and D. Fraser. 2003. Effects of three types of free-stall surfaces on preferences and stall usage by dairy cows. J. Dairy Sci. 86:521-529.

Tucker, C. B., D. M. Weary, M. A. G. von Keyserlingk, and K. A. Beauchemin. 2009. Cow comfort in tie-stalls: Increased depth of shavings or straw bedding increases lying time. J. Dairy Sci. 92:2684-2690.

Tuyttens, F. A. M. 2005. The importance of straw for pig and cattle welfare: A review. Appl. Anim. Behav. Sci. 92:261-282. 